\title{
Generalized Glycogenosis Type II (Pompe's Disease
}

\author{
M. R. NIHILL, ^ D. S. WILSON, and K. HUGH-JONES \\ From Westminster Children's Hospital, London
}

\begin{abstract}
Nihill, M. R., Wilson, D. S., and Hugh-Jones, K. (1970). Archives of Disease in Childhood, 45, 122. Generalized glycogenosis type II (Pompe's disease). The characteristic clinical features of 2 cases of Pompe's disease are presented, namely, signs of a cardiomyopathy with skeletal hypotonia and a characteristic ECG with a short PR interval and high voltage QRS complexes. Glycogen storage disease is confirmed by staining tissue such as lymphocytes, liver, or skeletal muscle with PAS, and the same tissues may be examined for glycolytic enzyme activity in order to characterize the type of glycogen storage disease present.
\end{abstract}

The clinical features of generalized glycogenosis affecting mainly the heart (Cori, Type II-Cori, 1954) were first described by Pompe in 1932 (Pompe, 1932; Putschar, 1932; Bischoff, 1932). Hers (1963) found that the accumulation of intracellular glycogen in all tissues of the body in Type II glycogenosis was due to an inherited deficiency of lysosomal $\propto$ 1-4, glucosidase (acid maltase). Ehlers reviewed the 54 cases described up to 1962 (Ehlers et al., 1962), and since then more than 24 other cases have been reported in the English literature (Caddell and Whittemore, 1962; Huijing, Van Creveld, and Losekoot, 1963; Crome, Cumings, and Duckett, 1963; Kahana et al., 1964; Ruttenberg et al., 1964; Lewis and Sutherland, 1964; Rosenstein, 1964; Hohn et al., 1965; PerezTreviño et al., 1965; Dinscoy et al., 1965; Hernandez et al., 1966; Cardiff, 1966; Hug et al., 1966; Smith, Amick, and Sidbury, 1966; Spach et al., 1966).

We report 2 cases, and discuss recent histochemical techniques which make it possible to diagnose this form of glycogen storage disease during life.

\section{Case Reports}

Case 1. This patient was the first-born female child of unrelated, healthy parents, delivered after a full-term, normal pregnancy, weighing $3.2 \mathrm{~kg}$. A paternal cousin has galactosaemia and another cousin has a heart murmur thought to be due to a small ventricular septal defect. There is no other history of heart disease or glycogen storage disease. She thrived well on breast milk until $5 \frac{1}{2}$ months when she developed a chest infection. Over the next few weeks, she became

Received 24 June 1969.

^Present address: Texas Children's Hospital, Houston, Texas, U.S.A. increasingly breathless and started refusing feed $\mathcal{S}_{\text {: }}$ by $7 \frac{1}{2}$ months, she had become lethargic and floppy and could no longer sit without support. She gradually lost weight and was finally admitted to hospital in heaut failure, aged 8 months.

On examination, she was an alert, pale, floppy ba他 lying in the frog position. Nutrition and muscle mass were normal. There was marked hypotonia such Qh she was unable to sit without support; reflexes diminished and sweating was excessive. Her tongue⿳亠丷⿵冂丶十⿻日乚 enlarged and protuberant which made feeding diffich She was dyspnoeic at rest, with subcostal recession and a prominent sternum. Her liver was enlarged $3 \mathrm{cr}$. below the right costal margin, but there was no cyanos or oedema. Pulse rate was 160 per minute and regulae, and the femoral pulses were easily felt. The apger beat was palpable just outside the anterior axillary line and tapping in quality. There was a third sound at the apex and a grade 2-3 mid-systolic murmur heard over the praecordium and loudest in the pulmonary area. There were fine crepitations with diminish breath sounds of bronchial quality over the left lowet lobe.

Investigations. $\mathrm{Hb}$, white cell count, blood urea, and serum electrolytes were normal. Serum bilirubin and alkaline phosphatase were normal. SGOT was IU and SGPT was 8 IU. Fasting blood glucose ws $84 \mathrm{mg} . / 100 \mathrm{ml}$. and an oral glucose tolerance test w normal. There were no reducing substances in the urine and the urinary amino acid chromatogram was normah A search for viruses was negative. Chest $x$-ray (Fig. du showed a grossly enlarged heart with a collapsed left low lobe. An ECG (Fig. 2) showed a PR interval of 0.08 sec్, wide amplitude QRS with an interval of 0.04-0.06 see There was left axis deviation of $+20^{\circ}$ and left ventiocular hypertrophy with $\mathrm{T}$ wave inversion in leads $\mathbf{T}$, III, aVR, and aVF, with ST depression in I, II, aVE? and aVF. 


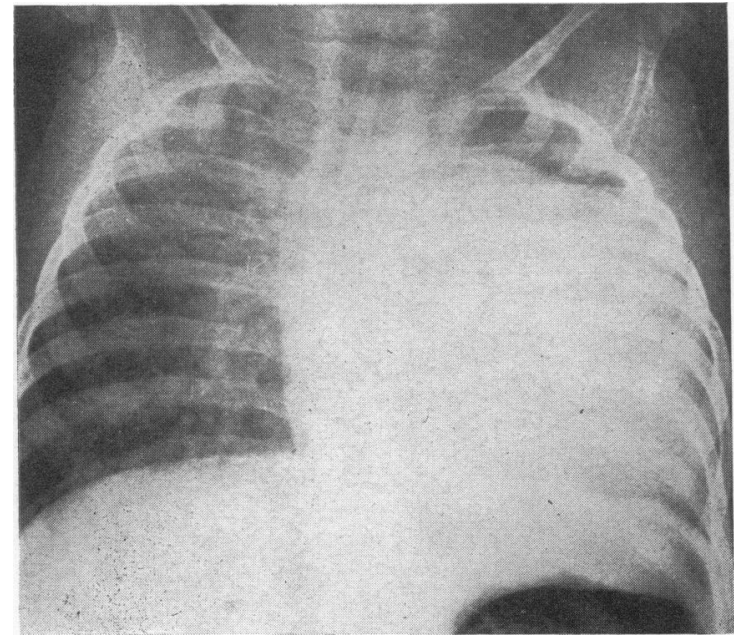

FIG. 1.-Chest x-ray, Case 1.

Electromyographic examination at 8 months showed findings typical of a myopathic process within the muscles with no evidence of denervation or motor nerve conduction defect.

Right heart catheterization and Elema Selective

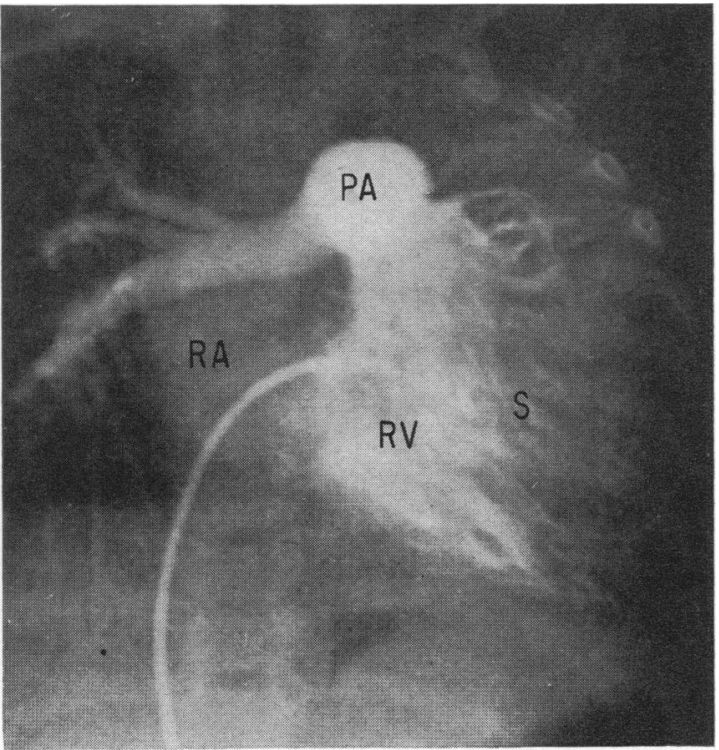

Fig. 3.-Angiocardiogram, Case 1. Right ventricular injection showing right ventricular cavity $(R V)$ distorted by thickened interventricular septum $(S)$. (RA, right atrium; $P A$, main pulmonary artery).

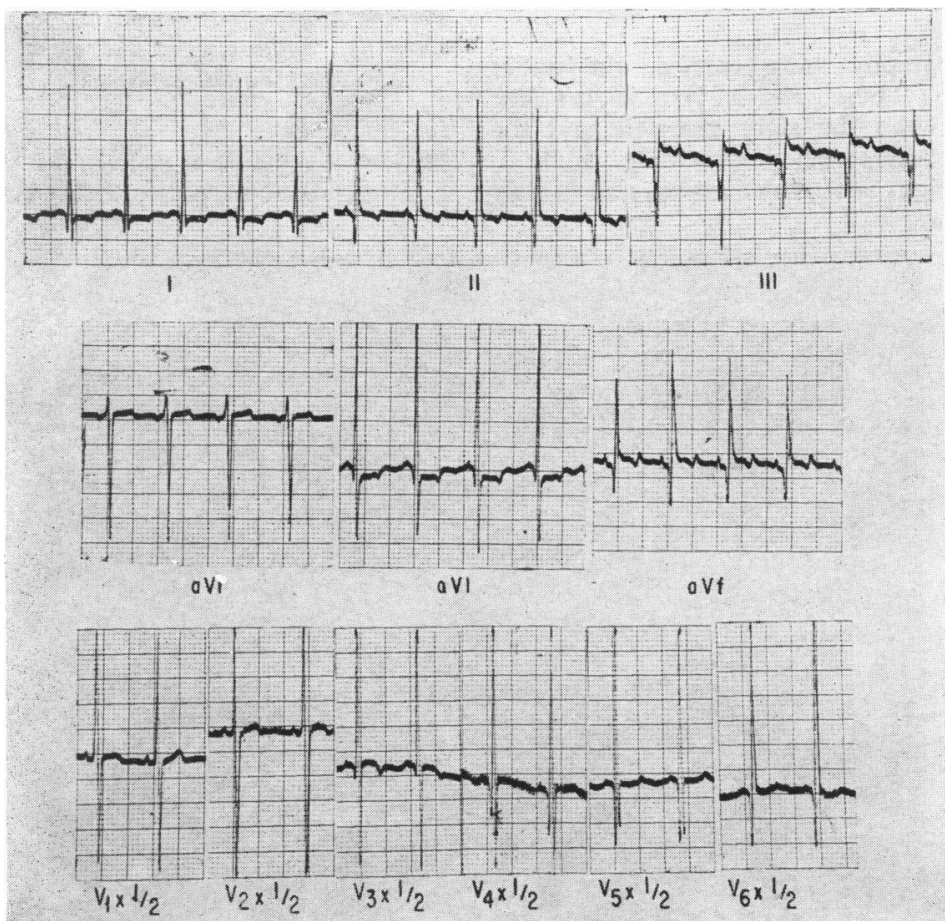

FIG. 2.-ECG, Case 1. Wide amplitude $Q R S$ complexes (half standard in leads aVL, aVF, and chest leads). Short $P R$ interval 0.08 sec., left axis deviation. 


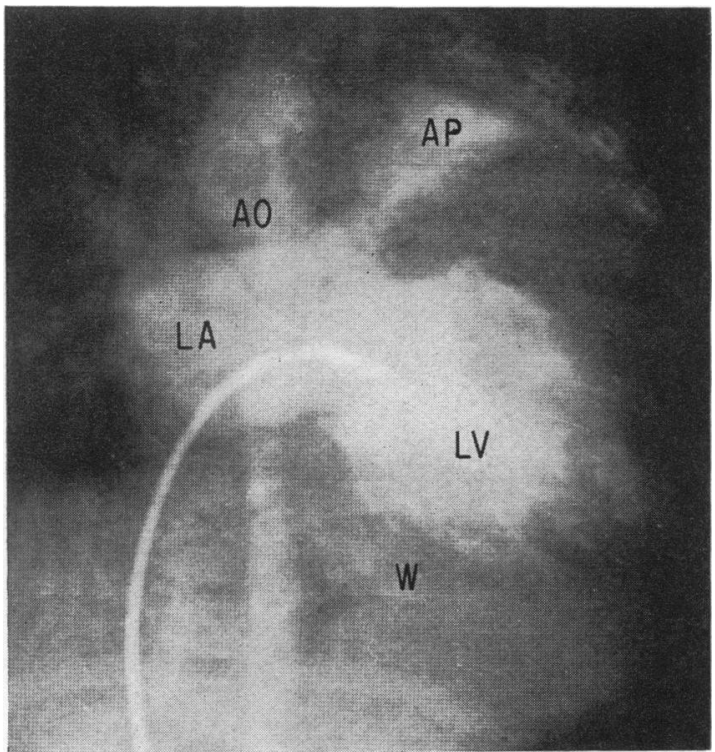

FIG. 4.-Angiocardiogram, Case 1, showing filling of left atrium $(L A)$ and upward displacement of left atrial appendage $(A P)$. Dilated left ventricular cavity $(L V)$ which contracted poorly. Left ventricle wall $(W)$ is grossly hypertrophied ( $A O$, aorta).

biplane angiocardiography were carried out under general anaesthesia. There was a systolic gradient of $12 \mathrm{~mm}$. $\mathrm{Hg}$ between the right ventricle and the pulmonary artery. Angiocardiography (Fig. 3, 4, 5) showed a distorted right ventricular cavity, and grossly

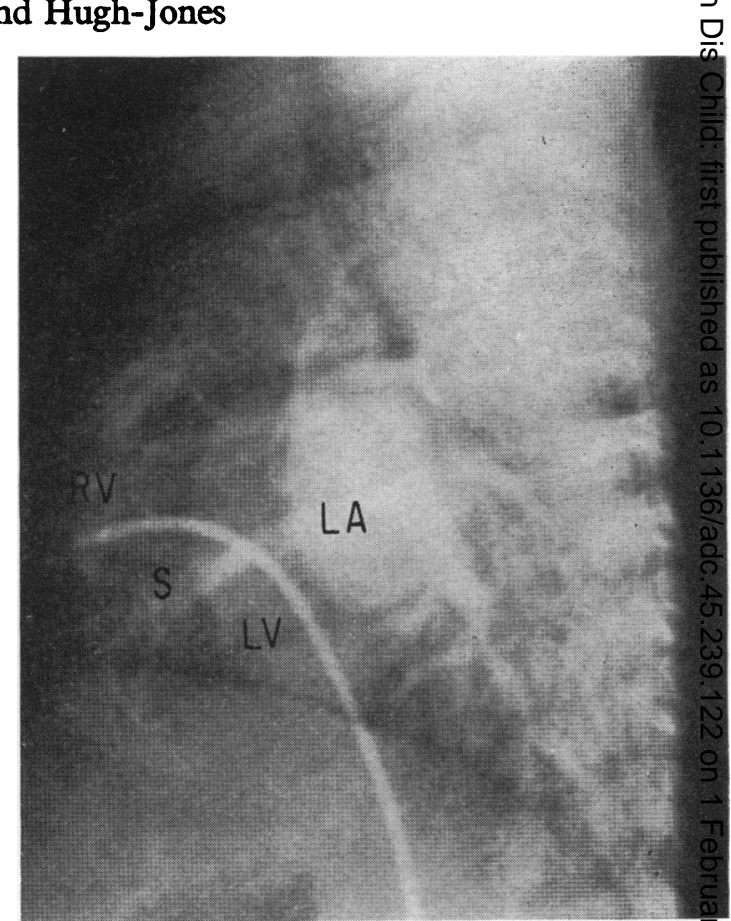

Fig. 5.-Lateral projection of angiocardiogram, Case showing filling of left atrium $(L A)$, left ventricle $(L V) \& u$ some dye remaining in the right ventricle $(R V)$. T्राte interventricular septum $(S)$ is much thickened.

thickened ventricular walls and interventricular septu椐. The clinical features of heart failure, a shortened $\mathrm{P}$.

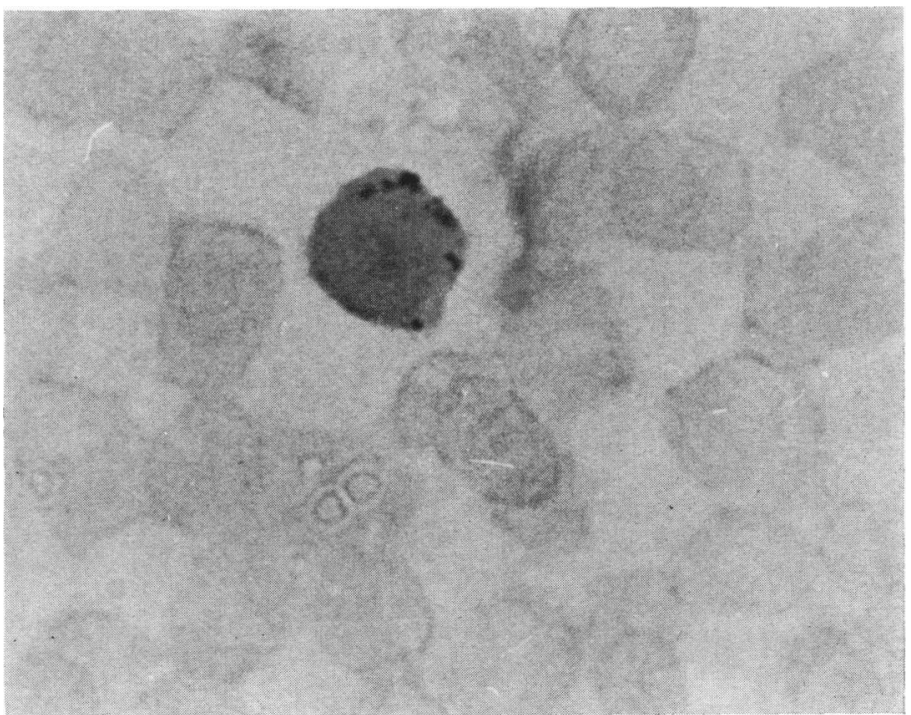

FIG. 6.-Lymphocyte from peripheral blood, showing large glycogen granules. $(P A S . \times 1200$. 


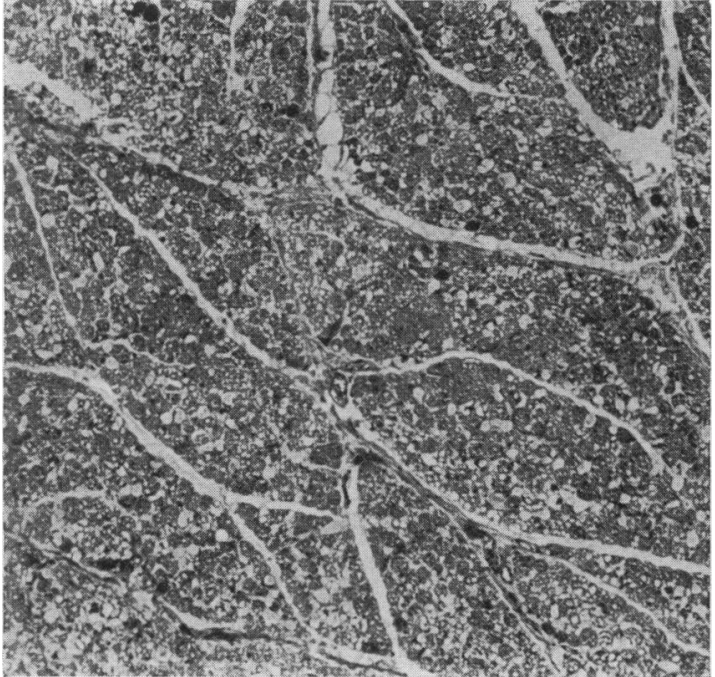

FIG. 7.-Cross-section of deltoid muscle showing vacuolization and granulation of the cytoplasm. ( $H$ and $E . \times 55$.)

interval with left axis deviation and left ventricular hypertrophy on the electrocardiogram, together with generalized muscular hypotonia, suggested the diagnosis of glycogen storage disease. Staining of peripheral blood lymphocytes with Periodic Acid Schiff (PAS) (Fig. 6), showed excessive glycogen granules in the cytoplasm. A biopsy was therefore taken from the deltoid muscle. One part was fixed in formol picric alcohol at $-20{ }^{\circ} \mathrm{C}$., and the other was fresh frozen and cut on a cryostat for enzymatic studies. Control muscle was taken from the sternomastoid of a patient of the same age. Histological section (Fig. 7) showed extremely bizarre muscle fibres with marked vacuolation and granulation in the cytoplasm, which caused enlargement of the individual fibres. Histologically, the granules and some of the material in the vacuoles were strongly positive to PAS and carmine stains (Fig. 8). However,

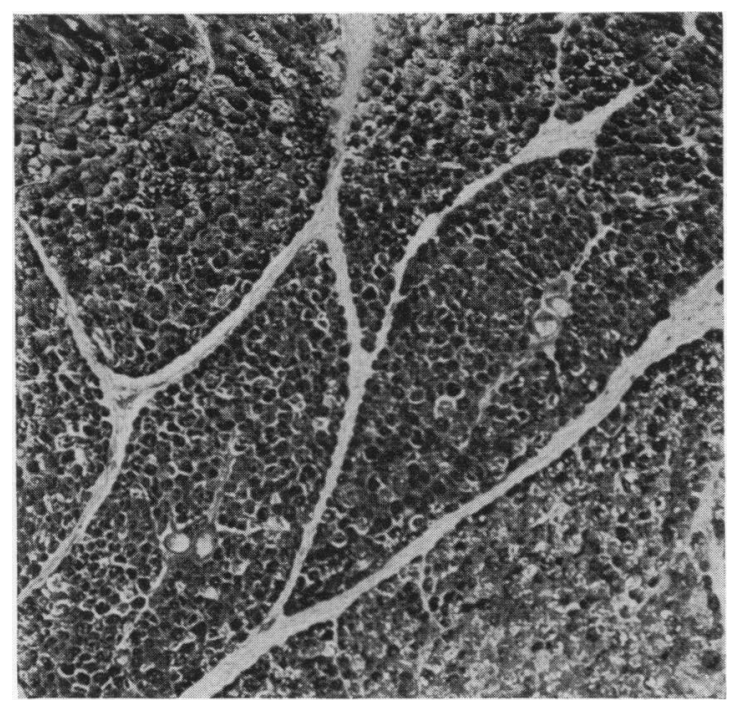

FIG. 8.-Deltoid muscle showing darkly stained glycogen granules. $(P A S . \times 55$. $)$

the staining in the vacuoles and the granules themselves disappeared after prior diastase digestion. This clearly indicates a marked excess of glycogen.

Fresh frozen muscle, peripheral lymphocytes, and red cells were examined for glycogen content and enzyme activity by Dr. H. Patrick at The Hospital for Sick Children, Great Ormond St. (Table). A marked deficiency of $\alpha 1-4$, glucosidase activity was demonstrated together with excessive accumulation of intracellular glycogen. Histochemical demonstration of other enzymes in the muscle tissue by Dr. I. Dawson, including glucose-6-phosphate dehydrogenase, 6-phosphogluconate dehydrogenase, $\mathrm{L}$ brancher enzymes, and glucose 6-phosphatase showed normal distribution. There was a slight reduction in the amount of amylophosphatase when compared with the normal control.

TABLE

Glycogen Content and $\alpha$-Glucosidase Activity in Various Tissues

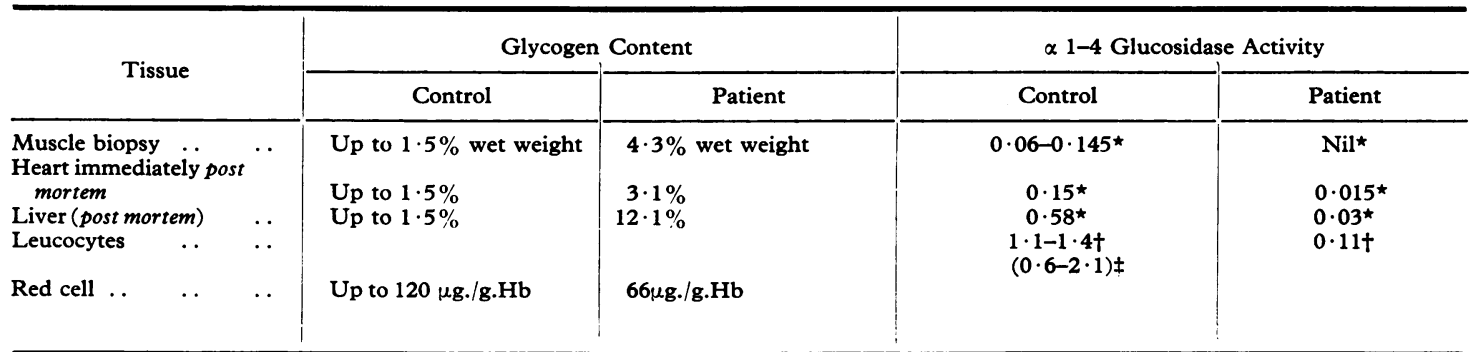

$\star$ Units $=\mu$ moles of maltose hydrolysed $/ \mathrm{min}$. per $\mathrm{g}$. wet weight

$\left.\begin{array}{l}\dagger \text { Units }=\text { m } \iota \text { moles of maltose hydrolysed/min. per mg. protein } \\ \ddagger \text { Figures from Brown and Zellweger (1966). }\end{array}\right\}$ Hers (1963) 


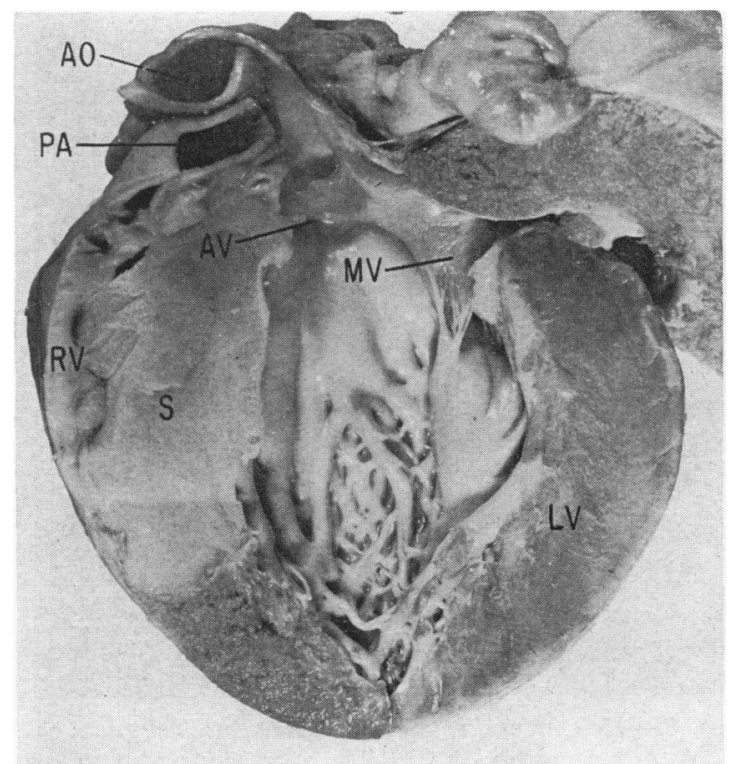

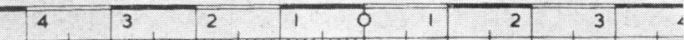

FIG. 9.-The heart of Case 1 with left ventricle opened to show grossly thickened left ventricular wall (LV) and septum $(S)$ with fibroelastosis of the left ventricular septal wall. The right ventricular cavity $(R V)$ is small and compressed by the thickened septum. ( $A O$, aorta; $P A$, main pulmonary artery; $A V$, aortic valve; $M V$, mitral valve.)

Clinical course. Her course in the hospital was marked by increasing hypotonia, difficulty with swallowing, and recurrent respiratory infections. The heart failure was reasonably well controlled with digoxin, mercaptomerin injections on alternate days, and nursing in humidified oxygen. Towards the end of her life, she required tube feeding and became centrally cyanosed without added oxygen, with resistant heart failure; she finally succumbed to a further chest infection, aged 11 months.

After death, needle aspiration specimens were taken from the heart and liver and immediately frozen at $-20{ }^{\circ} \mathrm{C}$. for estimation of glycogen content and acid maltase activity (Table). At necropsy, the heart (Fig. 9) was grossly enlarged and weighed $190 \mathrm{~g}$. (normal 40 g.). The enlargement was mainly left ventricular (wall $=20 \mathrm{~mm}$.), without valvular disease or anatomical abnormality. There was subendocardial fibrosis of the interventricular septum on the left side only. Reduction in the size of the right ventricular cavity was due to bulging of the septum, which was $20 \mathrm{~mm}$. thick. The right ventricular wall measured $7 \mathrm{~mm}$.

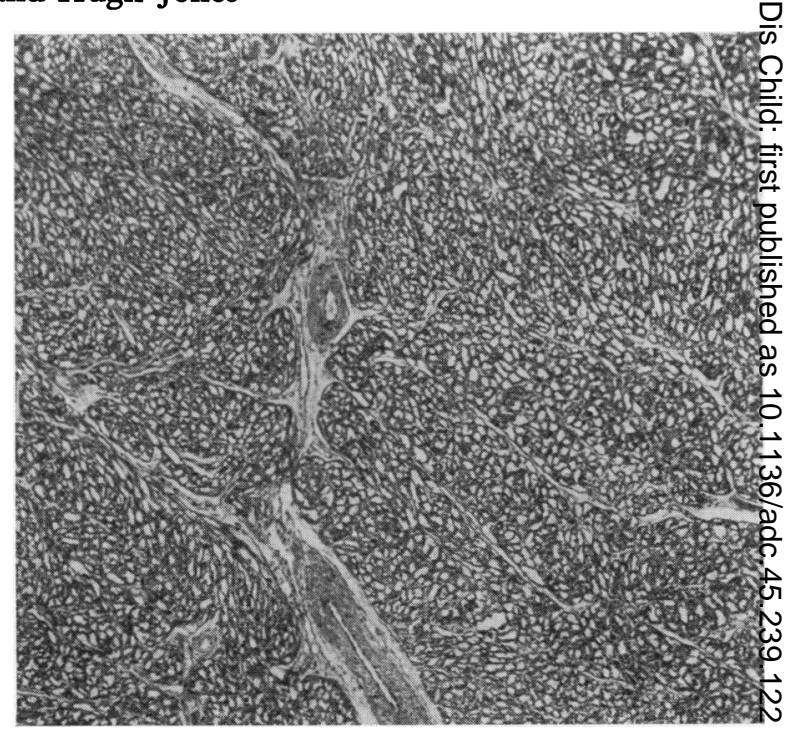

FIG. 10.-Section of myocardium showing lacework 윽 pattern caused by accumulation of intracellular glycogen granules. $(H$. and $E$. $\times 55$.)

Histological examination revealed heavy glycogen deposits in the cardiac muscle (Fig. 10), producing the typical lace-work pattern, and in skeletal muscle and $\overrightarrow{0}$ liver. Excessive glycogen was also found in the kidneys leucocytes of the spleen, bronchopneumonic exudat and to a lesser extent in the Purkinje cells of the cere bellum.

Blood from both parents was sent to Dr. David Hsia in Chicago for estimation of acid maltase activity.

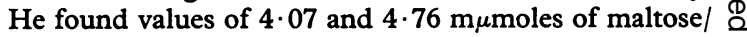
min. per mg. of protein in the mother's and father's $\overrightarrow{\vec{D}}$ blood respectively, while control blood showed activity of $6.36 \mathrm{~m} \mu$ moles of maltose/min. per mg. protein. Dr. Hsia considered these values to be in the heterozygous range.

Case 2. This patient was originally reported by Crome et al. in 1963 with special reference to the neurohistological changes in generalized glycogenosis. He was admitted to the Westminster Children's Hospital $\delta$ in 1961 for cardiovascular assessment and the clinical features and cardiac findings are reported again because 윽 of the marked similarity to Case 1 .

He was the second male child of healthy, unrelated $\frac{D}{O}$ parents, born after a normal pregnancy at full term, weighing $2.5 \mathrm{~kg}$. Apart from transient neonatal $\mathrm{N}$ asphyxia, there were no abnormalities noted, and he $\mathrm{N}$ thrived and was well until he was admitted to hospital $O$ at the age of 6 months for removal of a haemangioma $N$ on the left eyelid and right side of the neck. He suffered $\underset{<}{\sigma}$ a cardiac arrest while being intubated and after resuscita- 0 tion, he was found to have an enlarged heart.

On examination, he was a small baby weighing $5.6 £$ kg., with marked hypotonia and a high-pitched weak 
cry. The pulse rate was 124 per minute and all pulses were palpable. The apex beat was palpable in the mid-axillary line in the fifth interspace, and there was a soft third sound at the apex, but no murmurs were heard. The liver was palpable $2 \mathrm{~cm}$. below the right costal margin; there was no cyanosis or oedema, and the lung fields were clear.

A chest $x$-ray (Fig. 11) showed a grossly enlarged heart, and an ECG (Fig. 12) showed a PR interval of $0.08 \mathrm{sec}$., a wide amplitude QRS with an interval of $0.04-0.06$ sec. There was left axis deviation $\left(+20^{\circ}\right)$ and marked left ventricular hypertrophy. Deep $Q$ waves are seen in leads II, III, aVF, and V 3-6, with T wave inversion in leads I, II, aVL, and V3. A search for viruses was negative.

Progress. After the cardiac arrest, he developed cardiac failure with dyspnoea and a constantly enlarged liver in spite of digitalization and regular diuretics. Further chest infections developed, and the hypotonia became more severe, with difficulty in feeding, and he died at the age of 9 months.

Post-mortem findings. The heart was grossly enlarged, weighing $160 \mathrm{~g}$. (normal $38 \mathrm{~g}$.) with thickened ventricular walls (LV $20 \mathrm{~mm}$., RV $10 \mathrm{~mm}$.) and some endocardial thickening.

\section{Discussion}

Genetics. Pompe's disease is inherited as an

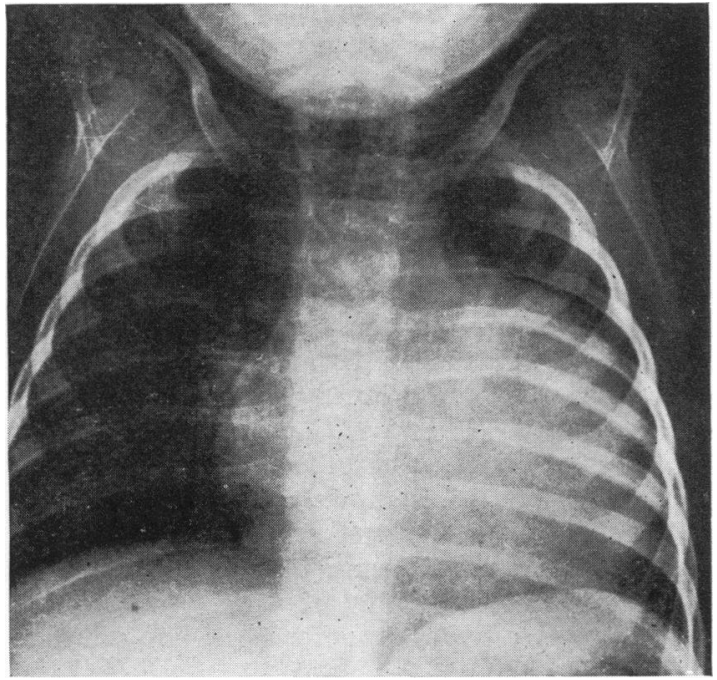

Fig. 11. Chest x-ray, Case 2.

autosomal recessive with equal sex distribution (Spach et al., 1966). Studies of heterozygotes have been few (Nitowsky and Grunfeld, 1967),

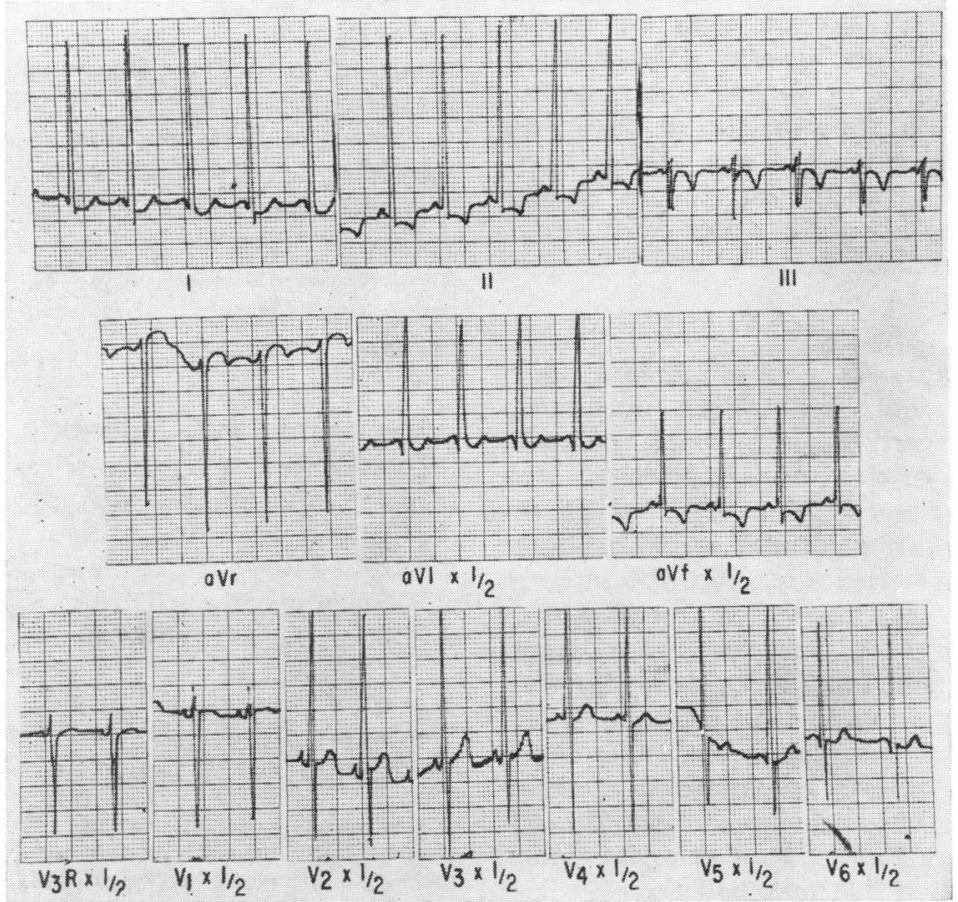

FIG. 12.-ECG, Case 2. Shortened PR interval $0.08 \mathrm{sec}$. with similar morphology to Case 1 (standardization $1 \mathrm{mV}-1 \mathrm{~cm}$. 
but Hsia (personal communication, 1968) considers the values for the enzyme activity obtained in the parents of our patients to be in the heterozygous range.

Pathogenesis. In Pompe's disease, absence of $\alpha$ 4-6 glucosidase from the intracellular lysosomes causes accumulation of structurally normal glycogen in lysosomal sacs where it is unavailable for normal degradation by glycolytic enzymes (Kahana et al., 1964). Some of the glycogen is seen to be dispersed throughout the cytoplasm on electron microscopy (Cardiff, 1966), and it has been postulated that other glycolytic enzymes may be absent in Pompe's disease (Brown and Zellweger, 1966). However, all clinical parameters of glycogen metabolism are normal, including the glucose tolerance test and responses to adrenalin and glucogen; hypoglycaemia does not occur in these patients.

Glycogen accumulates in all tissues of the body, particularly cardiac and skeletal muscle, and liver; it also accumulates in neurones of the central nervous system, spinal cord, and autonomic ganglia (Crome et al., 1963), which may cause symptoms of mental retardation, hypotonia, and constipation.

In this disease, cardiac and skeletal muscle contain between $3-10 \%$ glycogen, with an average content of $7.5 \%$ of wet weight. The heart is usually grossly enlarged, being 2 to 8 times normal weight (average 4 times normal in 58 cases), the left ventricle being twice the size of the right. Almost all cases developed heart failure, though in two cases described by Zellweger et al. (1965) aged 4 and 15 years, the heart was clinically unaffected.

Differential diagnosis. The differential diagnosis of the heart failure lies between endocardialfibroelastosis, myocarditis, anomalous coronary artery, or sclerosis of the coronary arteries. The one distinguishing feature in Pompe's disease is the ECG, which, according to Caddell and Whittemore (1962), has a characteristically short PR interval, of less than $0.09 \mathrm{sec}$. in $86 \%$ of cases, a wide amplitude QRS in $98 \%$, left ventricular hypertrophy in $65.7 \%$, and left axis deviation in $40 \%$ (the latter is usually found in older patients).

Heart failure is due to cardiomyopathy (Goodwin, 1967), caused by excessive accumulation of glycogen in the muscle fibres. Some cases develop fibroelastosis if they survive long enough. Hohn et al. (1965) estimated that over half the cases had evidence of outflow tract obstruction, as shown in Case 1, and in the case of Ehlers et al. (1962), and that this obstruction was probably the cause of the systolic murmur which had been heard in $47 \%$ of cases.

The chest $x$-ray shows gross cardiac enlargement-mainly left ventricular, very similar to castes of uncomplicated fibroelastosis, and the $x$-rays of the present cases are typical examples.

Muscle weakness was noted in $60 \%$ of reportiod cases and is due to a primary myopathy, as shown in the electromyogram, though anterior horn cofll infiltration (Crome et al., 1963), heart failure, and chest infection will accentuate this weakness. Macroglossia was also reported in $32 \%$ of casss and can suggest the appearance of cretinism $\mathrm{gr}$ Down's syndrome (Clement and Godman, 1950号

Special investigations. Confirmation of the diagnosis is most easily made by examination of the peripheral blood lymphocytes for glycogen content by periodic acid-Schiff staining, which normally does not show any glycogen granules in the cye plasm. The lymphocytes may also be examined for acid maltase activity (Huijing et al., 196ßె口). Liver and muscle biopsy specimens may be obtain by needle aspiration and give consistent results (H@g et al., 1966).

Cardiac catheterization and angiocardiograptay serve to rule out anatomical cardiac defects am abnormal coronary arteries, and may showôेtime greatly hypertrophied myocardium.

From the cases reported (Crome et al., 1963; Smith et al., 1966; Zellweger et al., 1965) and also the current case, excessive glycogen deposilits within the muscle produce an abnormal electromyographic pattern which is characteristic of $a$ myopathy. It seems that motor nerve conductiogn velocity is unimpaired.

Treatment. No treatment has so far beesn successful in this disease. Resection of the hypētrophied septum was attempted by Ehlers et (1962), but the patient died after the operation. Recently Hug and Schubert (1967) administered acid maltase extracted from Aspergillus niger-bgit the patient failed to show any marked improvemens.

We would like to thank Dr. H. M. T. Coles and Br. L. Crome for their permission to publish details fif Case 2. We would also like to thank Dr. H. Patrick and Dr. I. Dawson for enzyme and histochemical studies, Dr. Ian M. Anderson and Dr. M. Davidsón for cardiac catheterization and angiocardiography, Dr. J. I. Pugh for post-mortem findings, and the Department of Medical Illustration at the Westminster Hospital. 
REFERENCES

Bischoff, G. (1932). Zum klinischen Bild der GlykogenSpeicherungs-Krankheit (Glykogenose). Zeitschrift für Kinderheilkunde, 52, 722.

Brown, B. I., and Zellweger, H. (1966). $\alpha-1,4$-glucosidase activity in leucocytes from the family of two brothers who lack this enzyme in muscle. Biochemical fournal, 101, 16C.

Caddell, J., and Whittemore, R. (1962). Observations on generaliized glycogenosis with emphasis on electrocardiographic changes. Pediatrics, 29, 743.

Cardiff, R. D. (1966). A histochemical and electron microscopic study of skeletal muscle in a case of Pompe's disease. (Glycogenosis II). ibid, 37, 249.

Clement, D. H., and Godman, G. C. (1950). Glycogen disease resembling mongolism, cretinism and amytonia congenita. fournal of Pediatrics, 36, 11.

Cori, G. T. (1954). Glycogen structure and enzyme deficiencies in glycogen storage disease. Harvey Lectures, (1952-1953), 48, 145.

Crome, L., Cumings, J. N., and Duckett, S. (1963). Neurological and neurochemical aspects of generalized glycogen storage disease. Fournal of Neurology, Neurosurgery and Psychiatry, 26, 422.

Dinscoy, M. Y., Dinscoy, H. P., Kessler, A. D., Jackson, M. A., and Sidbury, J. B., Jr. (1965). Generalized glycogenosis and associated endocardial fibroelastosis. Report of 3 cases with biochemical studies. Fournal of Pediatrics, 67, 728.

Ehlers, K. H., Hagstrom, J. W. C., Lukas, D. S., Redo, S. F., and Engle, M. A. (1962). Glycogen-storage disease of the myocardium with obstruction to left ventricular outflow. Circulation, 25, 96.

Goodwin, J. F., (1967). The cardiomyopathies. Hospital Medicine, 1,1008

Hernandez, A., Jr., Marchesi, V., Goldring, D., Kissane, J., and Hartmann, A. F., Jr. (1966). Cardiac glycogenosis. Haemodynamic angiocardiographic and electron microscopic findings. Fournal of Pediatrics, 68, 400.

Hers, H. G. (1963). $\quad \alpha$-glucosidase activity in generalized glycogenstorage disease (Pompe's disease). Biochemical fournal, 86, 11.

Hohn, A. R., Lowe, C. U., Sokal, J. E., and Lambert, E. C. (1965). Cardiac problems in the glycogenoses with specific reference to Pompe's disease. Pediatrics, 35, 313.

Hug, G., Garancis, J. C., Schubert, W. K., and Kaplan, S. (1966). Glycogen storage disease types, II, III, VIII, and IX. American Fournal of Diseases of Children, 111, 457.
- and Schubert, W. K. (1967). Hepatic lysosomes in Pompe's disease: disappearance during glucosidase administration. fournal of Clinical Investigation, 46, 1073.

Huijing, F., Van Creveld, S., and Losekoot, G. (1963). Diagnosis of generalized glycogen storage disease (Pompe's Disease). fournal of Pediatrics, 63, 984.

Kahana, D., Telem, C., Steinitz, K., and Solomon, M. (1964). Generalized glycogenosis. Report of a case with deficiency of alpha glucosidase. ibid., 65, 243.

Lewis, G. M., and Sutherland, T. W. (1964). Sibs with cardiac glycogenosis. Archives of Disease in Childhood, 39, 523.

Nitowsky, H. M., and Grunfeld, A. (1967). Lysosomal $\alpha$-glucosidase in type II glycogenosis; activity in leukocytes and cell cultures in relation to genotype. Fournal of Laboratory and Clinical Medicine, 69, 472.

Perez-Treviño, C., Molina-Zapata, B., Guzman-Garcia, C., Merizalde, A., and Ricalde, A. (1965). Glycogen storage disease of the heart. American fournal of Cardiology, 16, 137.

Pompe, J. C. (1932). Over idiopatische hypertrophy van het hart. Nederlandsch Tijdschrift voor Geneeskunde, 76, 304.

Putschar, W. (1932). UUber angeborene Glykogenspeicherkrankheit des Herzens. 'Thesaurismosis glycogenica (v. Gierke).' Beiträge zur pathologischen Anatomie und zur allgemeinen Pathologie, 90, 222.

Rosenstein, B. J. (1964). Glycogen storage disease of the heart in a newborn infant. Fournal of Pediatrics, 65, 126.

Ruttenberg, H. D., Steidl, R. M., Carey, L. S., and Edwards, J. E. (1964). Glycogen-storage disease of the heart. Hemodynamic and angiocardiographic features in 2 cases. American Heart fournal, 67, 469.

Smith, H. L., Amick, L. D., and Sidbury, J. B., Jr. (1966). Type II glycogenosis. Report of a case with 4-year survival and absence of acid maltase associated with an abnormal glycogen. American Fournal of Diseases of Children, 111, 475.

Spach, M. S., Martin, A. M., Sidbury, J. B., Jr., Hackel, D. B., and Canent, R. V., Jr. (1966). Clinical pathological conference. (Case of Pompe's disease in infant). American Heart Fournal, 72, 265.

Zellweger, H., Brown, B. I., McCormick, W. F., and Tu, J. B. (1965). A mild form of muscular glycogenosis in two brothers with $\alpha-1,4$-glucosidase deficiency. Annales Paediatrici, 205, 413.

Correspondence to Dr. M. R. Nihill, Department of Pediatric Cardiology, Texas Children's Hospital, 6621 Fannin Street, Houston, Texas 77025, U.S.A. 